\section{Final diagnosis}

Keywords: haemobilia, hepatic artery aneurysm

Haemobilia due to a ruptured intrahepatic artery aneurysm.

1 Bolt RJ. Diseases of the hepatic blood vessels. In: Bockus HL, ed. Gastroenterology, 3rd edn, Philadelphia: Saunders, 1976; pp 471-91.

2 Kadir S, Athanasoulis CA, Ring EJ, Greenfield A. Transcatheter embolization of intrahepatic arterial aneurysms. Radiology 1980; 134: $335-9$.

3 Croce MA, Fabian TC, Sapiers JP, Kudsk KA. Traumatic hepatic artery pseudoaneurysm with hemobilia. Am $\mathcal{f}$ Surg 1994; 168: $235-8$
4 Reid C, Cameron D, Simon TA, Ives J, Hall JC. Selective embolisation of intrahepatic aneurysms. Aust NZ F Surg, 1992; 62: $582-4$

5 Baker KS, Tisnado J, Cho S-R, Beachley MC. Splanchnic artery aneurysms and pseudoaneurysms: transcatheter embolization. Radiology 1987; 163: 135-9.

\title{
Weight loss
}

D Scullion, A Al-Kutoubi

A 32-year-old Sudanese man presented with a three-month history of weight loss, night sweats and back pain. He also noticed an enlarging subcutaneous lump in the left loin. A plain chest Xray is shown in figure 1.

\section{Department of Diagnostic Radiology, St Mary's Hospital, London W2 1NY, UK D Scullion \\ A Al-Kutoubi \\ Correspondence to Dr Al- Kutoubi}

Accepted 14 August 1995

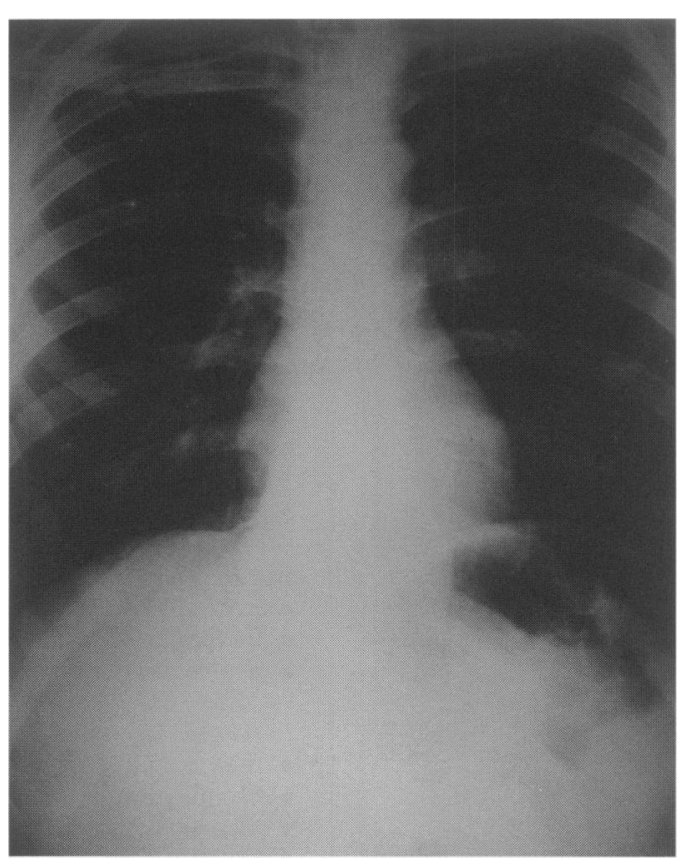

\section{Questions}

1 What is the most likely diagnosis?

2 What radiological investigations would you perform next?

Figure 1 Plain chest X-ray 


\section{Answers}

The chest X-ray shows an increased density behind the left heart border consistent with a paraspinal mass. The plain film of the thoracolumbar junction (figure 2) shows the elliptical mass clearly. Typical changes of tuberculous infection are seen in the vertebral bodies and T11/12 intervertebral disc. Computed tomography (CT) is the investigation of choice to

Figure 2 Plain film of the thoracolumbar junction showing a large paravertebral soft tissue mass (white arrows). There is sclerosis of the superior end plate of $\mathrm{T} 12$ with significant loss of height of the T11/12 intervertebral disc (black arrow)

Figure 3 CT scan. The paravertebral abscess is seen. The eccentric destruction of the body of T11 is apparent (arrow)

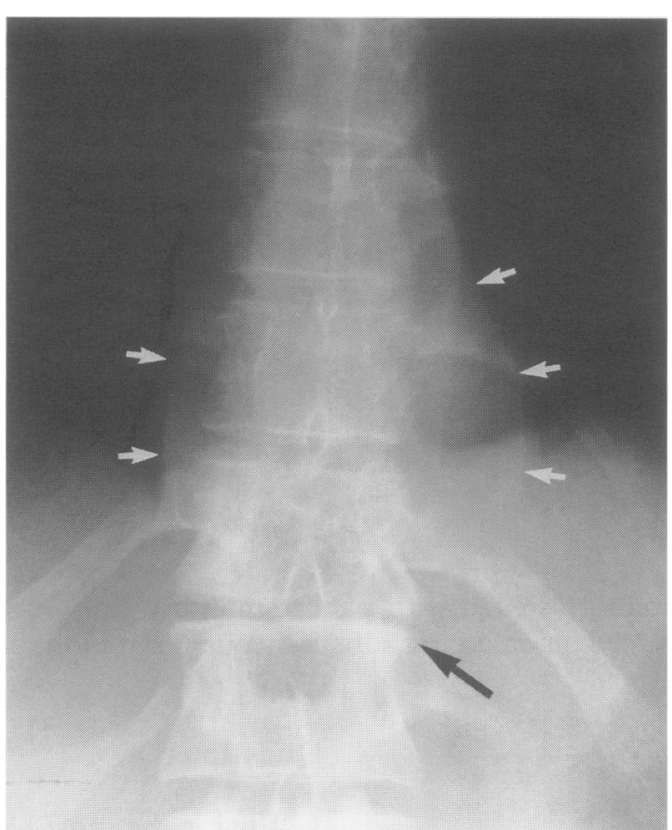

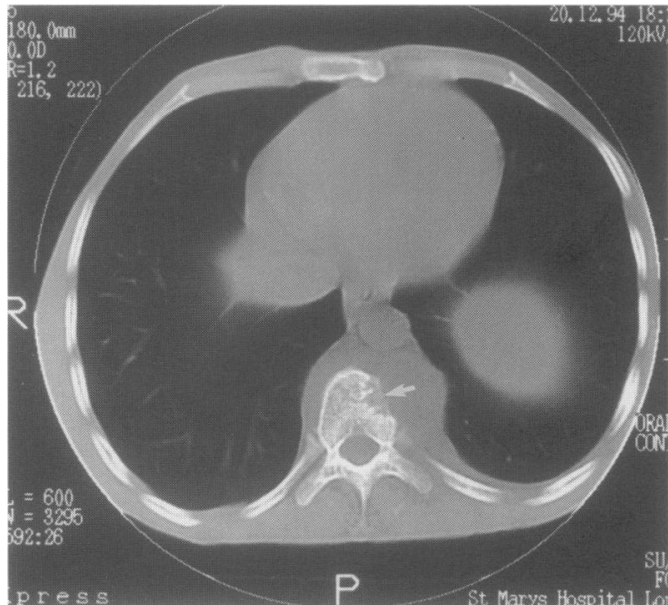

Figure 4 CT scan. The soft tissue settings show the paravertebral abscess draped anteriorly over the spinal column. On the left side it has penetrated the chest wall and involves the paraspinal muscles (arrow) further delineate the extent of disease (figures 3 and 4).

Spinal tuberculosis has been in existence for several thousand years. Its association with spinal deformity was first described by $\mathrm{Sir}$ Percival Pott in 1779. Untreated, it may also lead to serious neurological sequellae due to spinal cord compression. It is a common problem in India where it accounts for more than $50 \%$ of all forms of osteo-articular tuberculosis. Overall, children and young adults are affected most. It is assumed that the disease arises by haematogenous spread from pulmonary tuberculosis, although only $30 \%$ of patients will have evidence of active pulmonary disease at presentation. Although any bone may be affected, the spine is the commonest site of osteo-articular tuberculosis ${ }^{1}$ and is involved in approximately $50 \%$ of cases. The commonest site of spinal tuberculosis is the lower thoracic and upper lumbar spine. Usually the disease process involves the anterior aspect of the vertebral body, either at the inferior or superior margin. This predilection for the metaphysis also occurs in the long bones. Spread to the adjacent vertebral body often occurs via the intervertebral disc. The pattern of bony abnormalities may vary between caucasian and non-caucasian patients.

Caseous material may be extruded from the vertebral body and track beneath the anterior longitudinal ligament. The soft tissue mass often extends way beyond the area of bony abnormality. This may cause 'scalloping' of the vertebral bodies and eventually point onto the skin surface some distance from the original bony focus. Calcification within a paravertebral abscess is said to be pathognomonic for tuberculosis. It is important to realise that the soft tissue component may be extensive even when bony changes are subtle. CT is well suited to show the extent of both bony

\begin{tabular}{|l|}
\hline Spinal tuberculosis \\
\hline In caucasians \\
- involvement of intervertebral disc common \\
- predominantly lytic with little or no sclerosis \\
- involvement of posterior arch rare \\
In non-caucasians \\
- often confined to vertebral body \\
- disc may not be involved \\
- sclerosis common \\
\hline
\end{tabular}

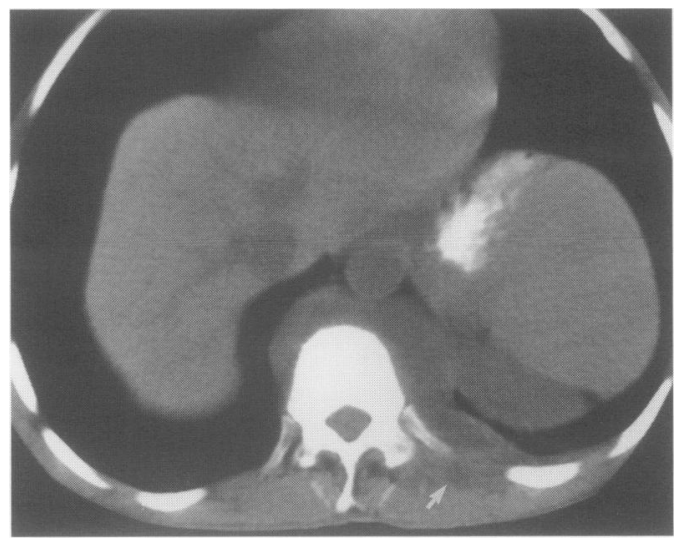

Box 1

Tuberculous spondylitis: keypoints

- the vertebral bodies are most often affected; the thoracolumbar junction is the commonest site

- bony changes may be subtle even in the presence of extensive soft tissue involvement

- CT or MRI is ideally suited to define the extent of the disease process 
destruction $^{2}$ and the paravertebral abscess, and in this respect is more sensitive than plain radiography. Aspiration of the abscess collection may also be performed under CT guidance to confirm the diagnosis, as was the case in this patient. Magnetic resonance imaging can also accurately define the extent of both bone and soft tissue disease. ${ }^{3}$

The major differential diagnosis is malignancy, both primary and secondary. This is not usually associated with loss of disc space height, although it may rarely occur with lymphoma and myeloma. Loss of the vertebral end plates tends to occur earlier in pyogenic

1 Chapman M, Murray RO, Stoker DJ. Tuberculosis of the bones and joints. Semin Roentgenol 1979; 14: 266-82.

2 Jain R, Sawhney S, Berry M. Computed tomography of veterbral tuberculosis: patterns of bone destruction. Clin Radiol 1993; 47: 196-9. osteomyelitis than in tuberculosis, but vertebral body subluxation may be seen in both conditions. In caucasian patients a marked periosteal reaction favours pyogenic infection. Other infections that may rarely cause a similar picture are fungi, actinomycosis, hydatid disease, and histoplasmosis.

\section{Final diagnosis}

Tuberculous spondylitis with paravertebral cold abscess.

Keywords: tuberculous spondylitis

3 Liu GC, Chou MS, Tsai TC, Lin SY, Shen YS. Magnetic resonance evaluation of tuberculous spondylitis. Acta Radio 1993; 34: 554-8.

\title{
An unusual but important cause of sciatica
}

\author{
SKC Toh, S Ellis, V Bahal
}

An 85-year-old man presented to the rheumatologist with a three-year history of increasingly severe lower backpain, radiating down both his legs, with reduced straight-leg raising and a positive sciatic-nerve stretch test. He had no urinary or bowel symptoms, and abdominal examination was unremarkable. As part of his management, he had an epidural with a local anaesthetic, resulting in acute urinary retention. Rectal examination performed after catheterisation revealed a 'pulsatile' prostate. Ultrasound scan (figure 1) and computed tomography (CT) (figure 2) of the pelvis were then obtained.

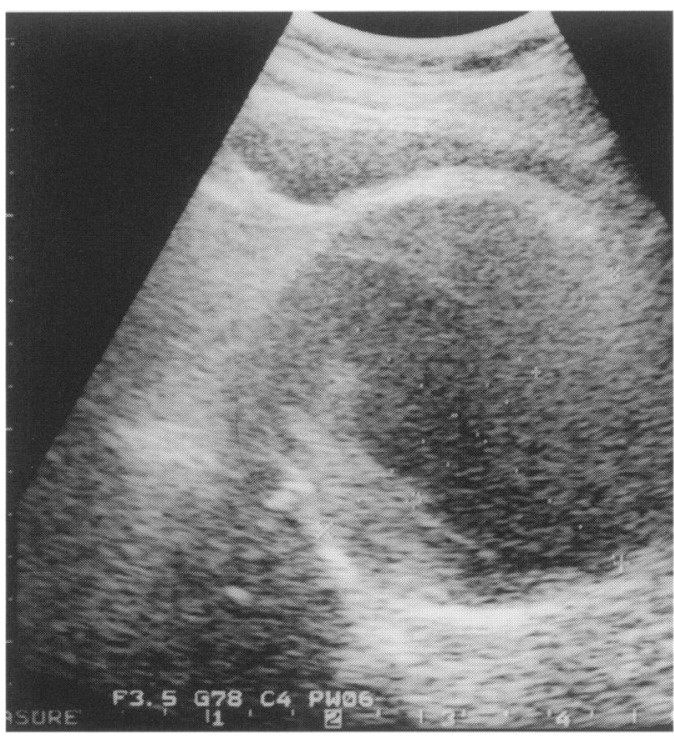

Figure 1 Ultrasound scan of the pelvis

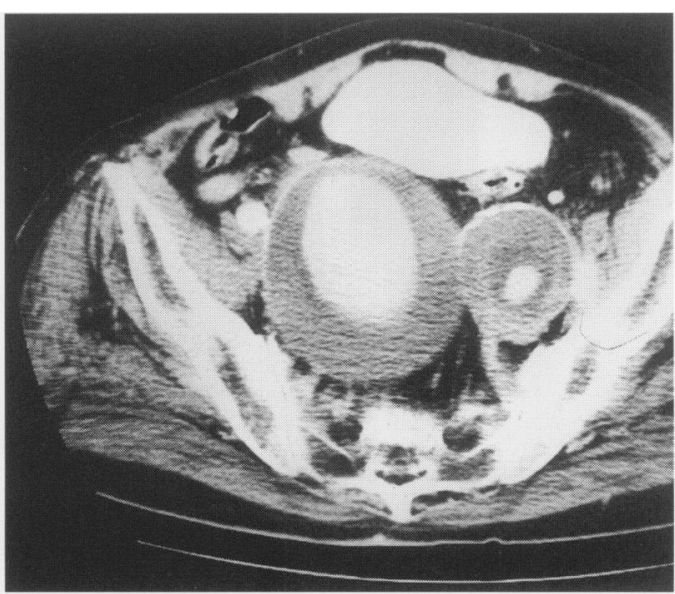

Figure 2 CT scan of the pelvis

East Surrey Hospital, Redhill, Surrey RH1 5RH, UK

SKC Toh

S Ellis

V Bahal

Correspondence to

SKC Toh, University

Surgical Unit, Southampton

General Hospital, Tremona

Road, Southampton

SO16 6YD, UK

\section{Questions}

1 What is the diagnosis?

2 How may this condition present?

3 What further investigations and management may be advised? 